\title{
Assessing the Relationship Between Commodity Chains: Ethanol, Corn and Chicken Meat
}

\author{
Eder Ferragi, Irenilza Nääs \\ Graduate Program in Production Engineering, Paulista University-UNIP, Bacelar St, 1212, São \\ Paulo, Brazil. \\ irenilza@gmail.com
}

\begin{abstract}
Energy and food are two issues of fundamental importance in the scenario of global production and consumption. This study seeks to describe, measure and analyze the interrelationship between the results of global commodity chains of corn, ethanol and broiler. We considered the interconnectivity through the chains inputs and outputs within the production of both food and biofuel. Based on the production of the three commodities in the United States and Brazil, the Social Network Analysis (SNA) metrics was used to calculate quantitative indicators of centrality (outdegree and indegree) of the products in relation to each other. The study allowed the identification of degree indices for each product at three different times over a period of twelve years. Results indicated the importance and evolution of the relationship between the outputs of each commodity chain throughout the studied period.
\end{abstract}

Keywords: agribusiness; social network analysis; interrelated global chains.

\section{Introduction}

According to the conceptual approach of the global commodity chain - GCC [1], the first dimension of the chain is an input - output structure, which describes the transformation process of raw materials and other inputs in the final products. In this approach, the ethanol, the corn and the broiler chains are interconnected. From a global point of view the final product of the corn chain can be an input of the ethanol chain, and both corn and ethanol chains outputs provide inputs for the broiler chain. A great part of the studies found in current literature define the border of the chain or network analysis based on one single product or commodity [2, 3, 4], and therefore, fail to consider important aspects that refer to the inter-relationship between one chain and another. Defined as a network of labor and production processes the supply chain concept surpasses the issues of the transformation processes and goes on to consider the ways in which people, places, and processes are related to each other in the global

adfa, p. 1, 2011.

(C) Springer-Verlag Berlin Heidelberg 2011 
economy [4]. The second dimension of the chain includes a configuration of geographical outline [1] considering transportation and communication, as well as institutional structures from each region, grounded in the world system theory [5]. According to this concept, it is understood that the productive processes is developed following a relationship based on some logic/concern between countries in the southern hemisphere and the northern hemisphere. The commodity chain approach becomes global and changes the focus of production in a specific country to a specific commodity. Consequently the focus is how the agents in the several countries cooperate or diverge from the rules to govern the chains and take ownership of the profits generated [6].

Given the relevance of agribusiness in the national and global scenario, the present study relates the total production of ethanol, corn and broiler chains in Brazil, and in the United States, the world's largest producers of these commodities [7]. The Social Network Analysis - SNA and the Graph theory [8] were applied in the quantitative analysis. A chain is composed of nodes and links, which connect the nodes. In the SNA the nodes (people or companies) are connected to each other through links, and patterns can be analyzed and calculated at two different levels: analysis of the nodes and analysis of the entire chain. In the first case, it is possible to assess the involvement and importance of a particular node about the complete chain $[9,10]$. It is possible to calculate centrality rates that measure the degree (the link's volume of direct relation with the other nodes), the closeness (the indirect linking capability with the other nodes in the chain), and the betweenness (which considers the possibility of relationship between different groups of nodes that compose the chain) [9].

Regarding the chain in its' completeness the SNA metrics allow the calculation of density, centralization and complexity rates, which enables the possibility to observe the organization of the whole chain from the point of view of the set of links of which it is composed of [11].

The present study aimed to identify a quantitative instrument that allow to indicate the importance degree of a commodity chain output in relation to others chain's outputs. We seek for contributing to the analysis of the global commodity chains and their inter-relations, both in particular moments as well as in their evolution through time.

\section{Methodology}

To analyze the relationship between the mentioned chains, the outputs were considered as the total production of each commodity (ethanol, corn, and broiler). It was assumed that the total of the annual production represents the result of a complex business that involves previous decisions based on price [12, 13], climate [14], availability of natural resources [15], labor [16], and economic and governmental politics [17], as well as an interaction with other areas of knowledge such as biology, agronomy, mechanics, chemistry, physics and sustainability $[18,19]$.

The values were obtained from the data published by the organizations USDA United States Department of Agriculture, RFA - Renewable Fuels Association, 
National Chicken Council, CONAB - Companhia Nacional de Abastecimento (National Supply Company), ÚNICA - União da Indústria da Cana-de-Açúcar (Brazilian Sugarcane Industry Association), e UBABEF - União Brasileira de Avicultura ( Brazilian Poultry Union). Although the measurements are expressed in different units by the countries, all of the values were transformed in metric tons $(1,000 \mathrm{~kg})$ for comparison purposes. The studied period covers the years 2000, 2006 and 2012 (Figure 1).

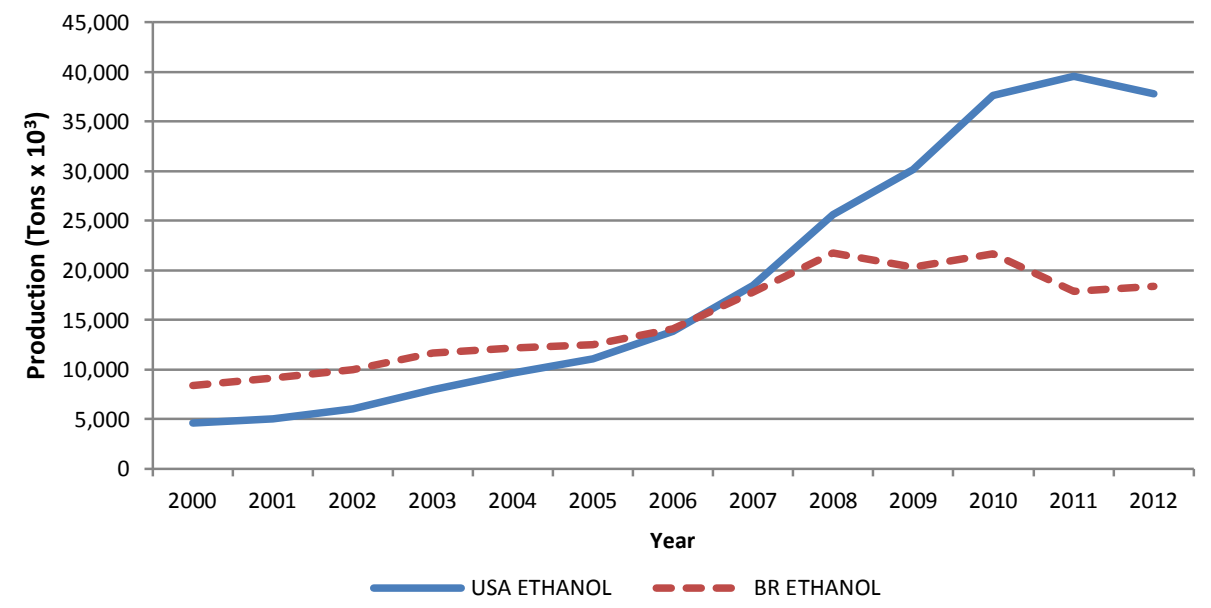

Fig. 1. American and Brazilian ethanol production from 2000 to 2012

To establish a comparison between the outputs of the chains, the proportions were calculated for each commodity production over the production of the other two. Values expressing the rate of the importance of each one over the two others were obtained, in terms of quantity produced in Brazil and in the United States, in the selected periods (Table 1). Ethanol, corn, and broiler were considered as nodes within a simplified network. The links between the nodes were quantified using the values expressed in Table 1.

Data were processed using the software UCINET [20] to identify the centrality index for each node indicating the outdegree, which evaluates the relationship of a product when compared to the others; and the indegree, indicating the relationship with the others to the same product [9].

Since graphic representation helps the understanding of the connections within a network [21], the software NetDraw 4.14 [22] along with the software UCINET for Windows was used to elaborate the graphics that shows the relationship between the three commodities production. 
Table 1. Compared production of Ethanol, Corn, and Broiler in the USA and Brazil

\begin{tabular}{|c|c|c|c|c|c|c|c|}
\hline & \multicolumn{3}{|c|}{ BRAZIL } & \multicolumn{3}{|c|}{ UNITED STATES } \\
\hline & & 2000 & 2006 & 2012 & 2000 & 2006 & 2012 \\
\hline \multicolumn{2}{|c|}{ PRODUCT } & \multicolumn{3}{|c|}{ Production* } & \multicolumn{3}{|c|}{ Production* } \\
\hline \multirow{2}{*}{\multicolumn{2}{|c|}{$\begin{array}{c}\text { Ethanol } \\
\text { Corn }\end{array}$}} & 8367.35 & 14096.81 & 18348.79 & 4635.72 & 13807.62 & 37825.20 \\
\hline & & 42289.70 & 51369.90 & 81007.20 & 251854.00 & 267503.00 & 273819.52 \\
\hline \multicolumn{2}{|c|}{ Broiler } & 5980.00 & 9340.00 & 12650.00 & 13702.80 & 15930.31 & 16621.08 \\
\hline \multicolumn{8}{|c|}{ RELATION } \\
\hline \multicolumn{2}{|c|}{$\mathrm{a} \quad \mathrm{b}$} & \multicolumn{3}{|c|}{ Ratio ** } & \multicolumn{3}{|c|}{ Ratio ** } \\
\hline Corn & Ethanol & 5.05 & 3.64 & 4.41 & 54.33 & 19.37 & 7.24 \\
\hline Corn & Broiler & 7.07 & 5.50 & 6.40 & 18.38 & 16.79 & 16.47 \\
\hline Ethanol & Corn & 0.20 & 0.27 & 0.23 & 0.02 & 0.05 & 0.14 \\
\hline Ethanol & Broiler & 1.40 & 1.51 & 1.45 & 0.34 & 0.87 & 2.28 \\
\hline Broiler & Corn & 0.41 & 0.18 & 0.16 & 0.05 & 0.06 & 0.06 \\
\hline Broiler & Ethanol & 0.71 & 0.66 & 0.69 & 2.96 & 1.15 & 0.44 \\
\hline
\end{tabular}

* Production $=10^{3}$ tons

$* *$ Ratio $=a / b$

\section{$3 \quad$ Results and Discussion}

According to the rates calculated in Table 1 and represented by the graphs in Figure 2, it was possible to establish and view the comparisons between one commodity (node) and the others.

The size of the nodes is proportional to the volume of the specific production. The lines that connect the nodes indicate the relationship between the volume of production of each good, and the numbers next to the nodes indicate the ratio between the production of a good versus the other one it is related to. It was possible to observe the relationship and the evolution of ethanol, corn, and broiler productions through time: in 2000, 2006 and 2012 in Brazil (Figure 2 a, b, c), and in the United States (Figure $2 \mathrm{~d}, \mathrm{e}, \mathrm{f}$ ).

The aim of the paper was the development of an indicator that enable to assess the ratio of an element (node) not only with one another, but with all the other elements (nodes) that are part of the network. The values of the networks structural properties were compared: density (the ratio of all ties that are actually present to the number of possible ties), degree centrality (which refers to the amount of immediate ties the actor has within the network, \%), closeness centrality (which relates the distance of an actor to all others in the networks by focusing in the distance from each actor to all others, \%), betweenness centrality (which views an actor as being in a favoured position to the extent that the actor falls on the geodesic paths between other peers in the network, \%), clustering coefficient (which refers to the average of the densities of the neighbourhoods of all actors), clique (which is a sub-set of a network in which the actors are more closely and intensely tied to one another than they are to other members of the network), $\mathrm{N}$-clique (which is used to define an actor as a member of a clique if they are connected to every other member of the group at a distance greater than 1, with $\mathrm{N}$ being the length of the path allowed to make a connection to all other members), node (which is the same as element or actor), edge (which is the same as 
relationship), and geodesic distance (which is the length of the shortest path between the actors). However, we focused on the indegree and outdegree of the networks studied.

Using the software UCINET, was possible to calculate the outdegree (which measures the degree of importance of each product over all the others), as well as the indegree (that measures the importance of all the others over it) [9, 24].

\section{BRAZIL}

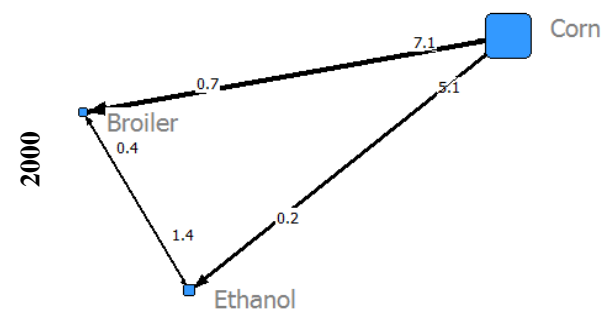

$\mathbf{a}$

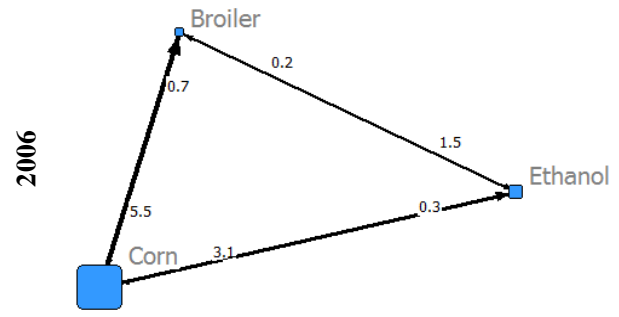

b

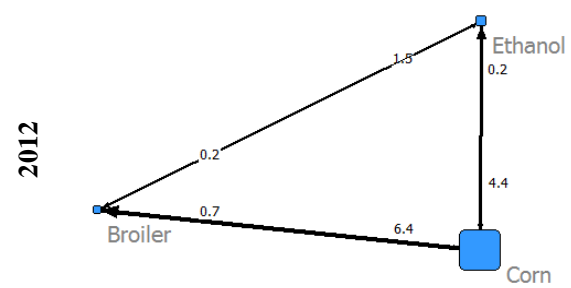

c
USA

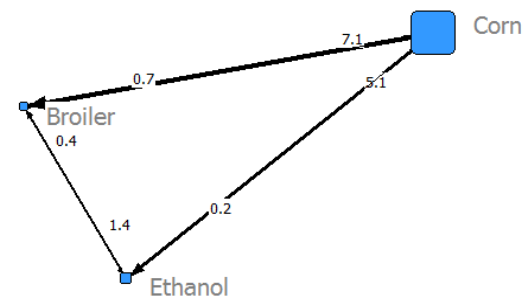

d
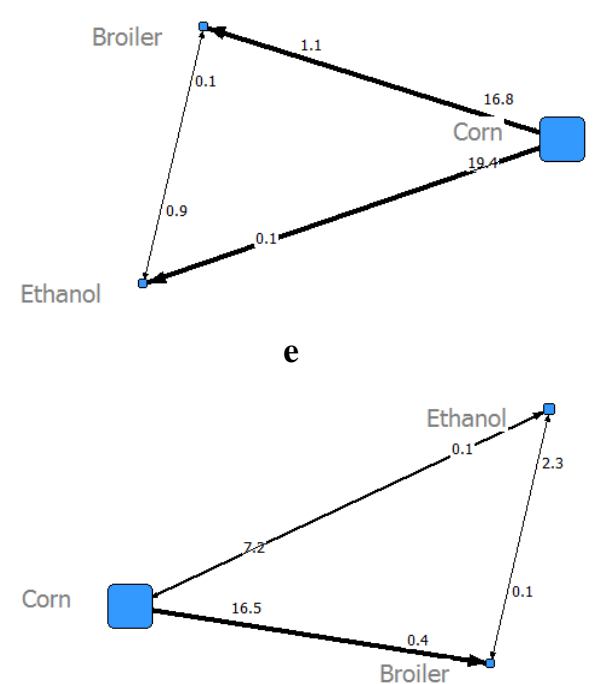

f

Fig. 2. Graphic representation of the relationship between ethanol, corn and broiler production in Brazil and in the U.S.A, from 2000 to 2012 .

Table 2 shows the indegree and outdegree of each product in Brazil and the United States during the period studied. Thus, a single indicator is introduced to assess the relation of production between a specific commodity with all the others considered in the chain or network. 
Table 2. Outdegree and indegree values of the ethanol, corn and broiler chains output

\begin{tabular}{crrrrrrrrrr}
\hline & \multicolumn{3}{c}{ BRAZIL } & \multicolumn{4}{c}{ UNITED STATES } & \multicolumn{3}{c}{ TOTAL } \\
\hline & 2000 & 2006 & 2012 & 2000 & 2006 & 2012 & 2000 & 2006 & 2012 \\
OUTDGREE & & & & & & & & & \\
Ethanol & 160 & 178 & 168 & 036 & 092 & 242 & 070 & 119 & 208 \\
Corn & 1212 & 914 & 1081 & 7271 & 3616 & 2371 & 3756 & 2405 & 1844 \\
Broiler & 085 & 084 & 085 & 301 & 121 & 050 & 158 & 099 & 060 \\
INDEGREE & & & & & & & & & \\
Ethanol & 576 & 430 & 510 & 5729 & 2052 & 768 & 2413 & 1234 & 684 \\
Corn & 034 & 045 & 039 & 007 & 011 & 020 & 011 & 017 & 024 \\
Broiler & 847 & 701 & 785 & 1872 & 1766 & 1875 & 1560 & 1372 & 1404 \\
\hline
\end{tabular}

The results obtained in Brazilian data indicate a relatively smooth trajectory for the three commodities considered. In the case of the ethanol derived from cane sugar, the outdegree slightly increased, ranging from 1.60 in 2000 to 1.68 in 2012 . The corn showed a slight decline of its outdegree, ranging from 12.12 to 10.81 . No change in the broiler's importance degree compared to the other two commodities was observed at the same period. These indicators reinforce the lack in Brazilian policy to encourages biofuel production [25], neither to favor the production of grain, feed and poultry, whose advances occur despite the financial constraints, lack of supportive transport logistics and distribution infrastructure [26, 27].

On the other hand, in the United States, the evolution of the degree of importance of ethanol when compared to the decrease of the importance of corn and chicken, confirm both the policy of encouraging the production of renewable energy as an alternative to fossil fuels derived from oil [28, 29, 30], as well as the productivity leap achieved by ethanol chain, whose outdegree jumped from 0.36 in 2000 to 2.42 in 2012. The evolution of the importance of ethanol in the last twelve years occurs despite the outdegree declined of the corn, its main raw material, from 72.71 to 23.71 ; and also the chicken outdegree decreased from 3.01 to 0.50 which used the same corn as a feedstock.

Considering the production total amount of the three commodities in both the United States and Brazil, it was detected a large increase in importance in the biofuel chain over the food chains (corn and broiler). The evolution of the ethanol outdegree from 0.70 in 2000 to 2.08 in 2012, compared with the food chains such as corn and broiler which outdegree decreased from 37.56 to 18.44 and from 1.58 to 0.60 respectively in the same period, have contributed with quantitative evidences to the food versus fuel discussion.

\section{Conclusions}

The values of outdegree and indegree were obtained for the three simplified studied commodity chains, using the SNA concept. The calculation of these values and the visualization of the network allow assessing the output behavior of a chain, about 
one another over time. Further studies are recommended to include the full extent of the commodity chain to have a more precise view of the interrelations of the agribusiness chains.

\section{References}

1. Gereffi, G.: The organization of buyer-driven global commodity chains: How U.S. retailers shape overseas production networks. In: Gereffi, G., Korzeniewicz, M. (eds.) Commodity chains and global capitalism, pp. 95-122. Westport, CT: Praeger (1994)

2. Thompson, G.F.: Between hierarchies and markets: The logic and limits of network forms of organization. Oxford University Press, New York (2003)

3. Talbot, J.M.: The comparative advantages of tropical commodity chain analysis. In: Bair, J. (ed.) Frontiers of commodity chain research, pp. 93-109. Stanford University Press, California (2009)

4. Bair, J.: Global commodity chains - Genealogy and review. In: Bair, J. (ed.) Frontiers of commodity chain research, pp.1-34. Stanford University Press, California (2009)

5. Wallerstein, I.: The rise and future demise of the world capitalism system: Concepts for comparative analysis. Comparative Studies in Society and History. 16(4), 387-415 (1974)

6. Talbot, J.M.: Tropical commodity chains, forward integration strategies, and international inequality: coffee, cocoa and tea. Review of International Political Economy. 9(4), 701734 (2002)

7. Ferragi, E.M., Nääs, I.A.: Ethanol, corn and broiler: The interdependence between the global chains. Brazilian Journal of Biosystems Engineering. 9(1), 01-10 (2015)

8. Borgatti, S.P., Mehra, A., Brass, D. J., Labianca, G.: Network analysis in the social sciences. Science. 323, 892-895 (2009)

9. Freeman, L. C.: Centrality in social networks: Conceptual clarification. Social Networks. 1, 215-239 (1978)

10. Wasserman, S., Faust, K.: Social Network Analysis: Methods and Applications. Cambridge University Press, Cambridge (1994)

11. Kim,Y., Choi, T.Y., Yan, T., Dooley, K.: Structural investigation of supply networks: A social network analysis approach. Journal of Operations Management. 29, 194-211 (2011)

12. Mitchell, D.: A note on rising food prices. World Bank Policy Research Working Paper 4682. The World Bank Development Prospects Group, http://econ.worldbank.org (2008)

13. Ajanovic, A.: Biofuels versus food production: Does biofuels production increase food prices? Energy. 36(4), 2070-2076 (2011)

14. Lobell, D.B., Schlenker, W., Costa-Roberts, J.: Climate Trends and Global Crop Production Since 1980. Science. 333, 616-620 (2011)

15. Nusser, S.M., Goebel, J.J.: The National Resources Inventory: a long-term multi-resource monitoring programme. Environmental and Ecological Statistics. 4(3) 181-204 (1997)

16. Radhakrishna, R.: Agricultural Growth, Employment, and Poverty: A Policy Perspective. Economic and Political Weekly. 37 (3), 243-245+247-250 (2002)

17. Krueger, A. O., Schiff, M., Valdés, A.: Agricultural Incentives in Developing Countries: Measuring the Effect of Sectoral and Economywide Policies. World Bank Economic Review. 2(3), 255-271 (1988)

18. Demirbas, A.: Political, economic and environmental impacts of biofuels: A review. Applied Energy. 86, Supplement 1, S108-S117 (2009)

19. US EPA - U.S. Environmental Protection Agency. National Agriculture Center. http://www.epa.gov/agriculture/ag101/printcrop.html 
20. Borgatti, S.P., Everett, M.G., Freeman, L.C.: UCINET ® 6.0. Natick, MA: Analytic Technologies (2002)

21. Hanneman, R. A., Riddle, M.: Introduction to social network methods. University of California, Riverside (2005) http://faculty.ucr.edu/ hanneman/

22. Borgatti, S.P.: NetDraw Software for Network Visualization. Analytic Technologies: Lexington, KY (2002)

23. Studder, D.: Data visualization and discovery for better business decisions. TDWI best practices report. TDWI research (2013) http://tdwi.org

24. Opsahl, T., Agneessens, F., Skvoretz, J.: Node centrality in weighted networks: Generalizing degree and shortest paths. Social Networks. 32(3), 245-251 (2010)

25. Farina, E., Rodrigues, L., Souza, E. L.: A política de petróleo e a indústria de etanol no Brasil. Interesse Nacional. Julho/Setembro, 64-75 (2013)

26. Valdes, C., Lopes, I. V., Lopes, M. R.: Changing food demand challenges Brazil's farm sector. Brazilian Agriculture. October 2009, 27-33 (2009)

27. EMBRAPA, Empresa Brasileira de Pesquisa Agropecuária. Embrapa Milho e Sorgo (2012) https://www.embrapa.br/milho-e-sorgo

28. Figueira, S.R., Burnquist, H. L.: Programas para álcool combustível nos Estados Unidos e possibilidades de Exportação do Brasil. Agric. São Paulo. 53, 5-18 (2006)

29. Sorda, G., Banse, M., Kemfert, C.: An overview of biofuel policies across the world. Energy Policy. 38, 6977-6988 (2010)

30. Banerjee, A.: Food, Feed, Fuel: Transforming the competition for grains. Development and Change. 42, 529-557 (2011) 